\title{
On Deformability of Crane Metallic Structures
}

\author{
Anatoly Vershinsky ${ }^{*}$, Aleksandr Shubin and Aleksander Masyagin \\ Bauman Moscow State Technical University, Moscow, Russia
}

\begin{abstract}
Problems of metallic crane structure deformability are considered. This paper contains results of experimental studies on deformability of overhead crane beam elements. These studies take into account the specific interaction between stresses arising from the product's exposure to loads at various stages of its life cycle, from manufacturing to operation, and residual welding stresses. Recommendations are provided to help stabilize the dimensional parameters of a crane metallic structure.
\end{abstract}

\section{Introduction}

Paper [1] considers both general and specific industrial safety matters, i.e. safety related to lifting cranes that are essentially potentially dangerous technical devices. Crane metallic structures are extensively examined. In particular, in chapter 13 it is suggested to use the limit state of a crane's load-bearing metallic structure, i.e. maximum permissible deformation corresponding to yield strength, as one of the criteria for calculating crane residual lifetime. An example is given on how to calculate the crown value for main beams of a foundry crane [2-3].

It should be immediately noted that at present crane metallic structures are manufactured by welding [4-7]. Therefore, calculations related to deformability of their individual elements and complete structure must employ a unified design and process approach. The stress-strain state of any welded structures must take into account their deformability at all stages of a product's life: assembly, welding, transportation, mounting, operation, and refurbishment. Thus, overhead crane longitudinal beams deflection, which is critical for serviceability limit states (developing excessive deformations caused by exposure to loads and resulting in interruption of normal operation), in general is given by

$$
f=f_{\text {def }}+f_{\text {as }}+f_{\text {we }}+f_{n}+f_{q}+f^{\prime}{ }_{\text {res }},
$$

where $\mathrm{f}_{\text {des }}$ is design deflection;

$$
\mathrm{f}_{\text {des }}=\mathrm{f}_{\mathrm{cr} \text {, }}
$$

$\mathrm{f}_{\mathrm{cr} .}$ is the crown in vertical plane;

$\mathrm{f}_{\mathrm{des}}=0$ in the horizontal plane;

$\mathrm{f}_{\text {ass }}$ is beam deflection caused by assembly operations at various stages of longitudinal beam assembly, including as a component of the complete bridge at the final stage;

\footnotetext{
Corresponding author: rk4@bmstu.ru
} 
$\mathrm{f}_{\text {we }}$ is beam deflection as a result of making welding joints, which leads to $\mathrm{f}$ variations in different directions;

$\mathrm{f}_{\mathrm{n}}$ is beam deflection through exposure to external concentrated and moving loads;

$\mathrm{f}_{\mathrm{q}}$ is beam deflection under the action of its own weight;

$f$ ' res is beam deflection caused by interaction of residual welding stresses with the stresses under process (at all manufacturing stages) or accidental strength loads at manufacturing stages, during transportation and mounting, as well as stresses under working loads.

All addends in formula (1) are of the same order. Frequently, $f$ ' res values are also significant for the operation of both beam and truss crane structures. They are referred to as secondary welding deformations [8-11].

\section{Methods}

Paper [3] provides a design schematic (Fig. 1) for determination of beam residual deformations under bending as a result of the interaction between external load stresses after completing girth welds $\mathrm{P}$ (Fig. 1a) and residual welding stresses from longitudinal welds (Fig. 1b).

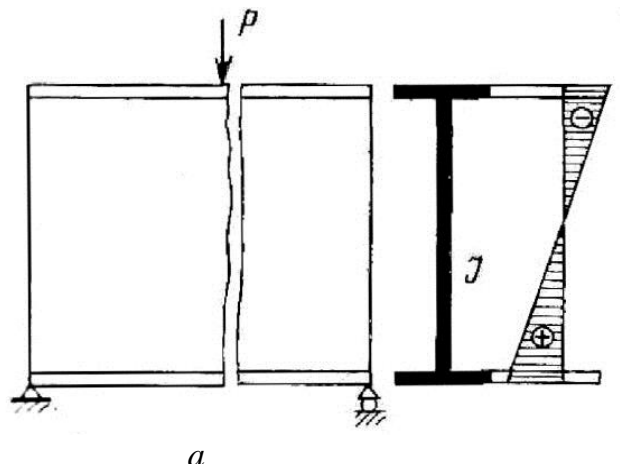

$a$

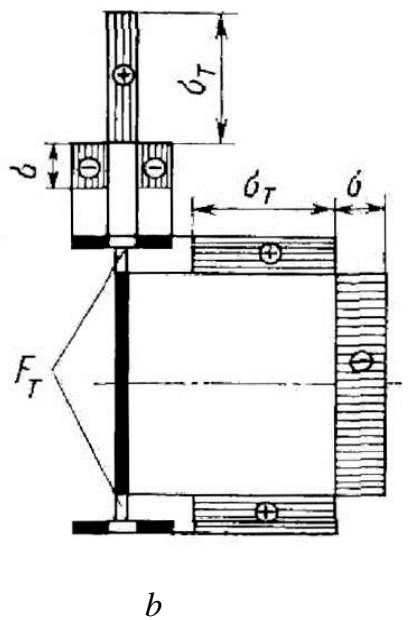

$b$

Fig. 1. Schematic for determining residual deformations under bending for a welding element $\left(F_{\mathrm{T}}\right.$ is the zone of residual tensile stresses, where $\sigma_{\text {res }}=\sigma_{\mathrm{T}}$ ) [8]

Residual welding stresses in the joining zone reach the yield strength $\sigma_{\mathrm{T}}$ for steel structures. Their interaction with the external load stresses produces elastoplastic deformations and, as a result, residual movements in the structure (deflection, angle of rotation, etc.).

Because bridge type beam structures contain a large amount of welding joints located along the beam longitudinal axis (longitudinal corner welds, including girth welds) and along the transverse axis (transverse welds for welding up the diaphragms), and each of them contributes to the product's strain-stress state, it is the most feasible to use the experimental method of study.

Therefore, multiple tests were carried out on beam models made of St 3 steel. The beams were subjected to transverse bending under one-time static and periodic loading in the span midpoint, as well as under moving load. Beam measurements for recording residual deflections were made using a measuring rod with dial gauge indicators with the scale interval of $0.01 \mathrm{~mm}$ fixed on it. 
Individual test results are shown in Fig. 2 and 3. The largest residual deflections are located on welded beams with transverse welds (Fig. 2). On the welded beam with transverse welds the residual deflection on wall and flange amounted to $0.41 \mathrm{~mm}$ with the stress under force P equal to $\sigma=170 \mathrm{MPa}$, on the beam with transverse welds only on the wall it amounted to $0.30 \mathrm{~mm}$, while on the welded beam without transverse welds the residual deflection was $0.23 \mathrm{~mm}$ at $\sigma=80 \mathrm{MPa}$.

Welded beams are characterized by a higher rate of residual deflection stabilization compared to rolled beams. In the allowable range of external load stresses it is achieved after $210^{3}$ cycles.

Experimental results of loading welded box-section beams confirm a similar behavior in terms of deformations development. Tests were carried out on a beam with the span of $1000 \mathrm{~mm}$ at the loading frequency of 300 cycles per minute. Deformation characteristics stabilization (residual deflection increment is zero) occurs after $10^{4}$ and $25 \times 10^{3}$ loading cycles for box-section and H-beam, correspondingly. If the experiment is continued up to $10^{5}$ loading cycles, incrementation of residual deflection is not observed.

The nature of residual deflection development under loading and during the tests of box-section beams with a 3,000 mm span and cross-section height of $170 \mathrm{~mm}$, is maintained. Similar to other scenarios that have been studied, residual deflection appears at the stress level in the beam midsection that is significantly less than the material yield strength.
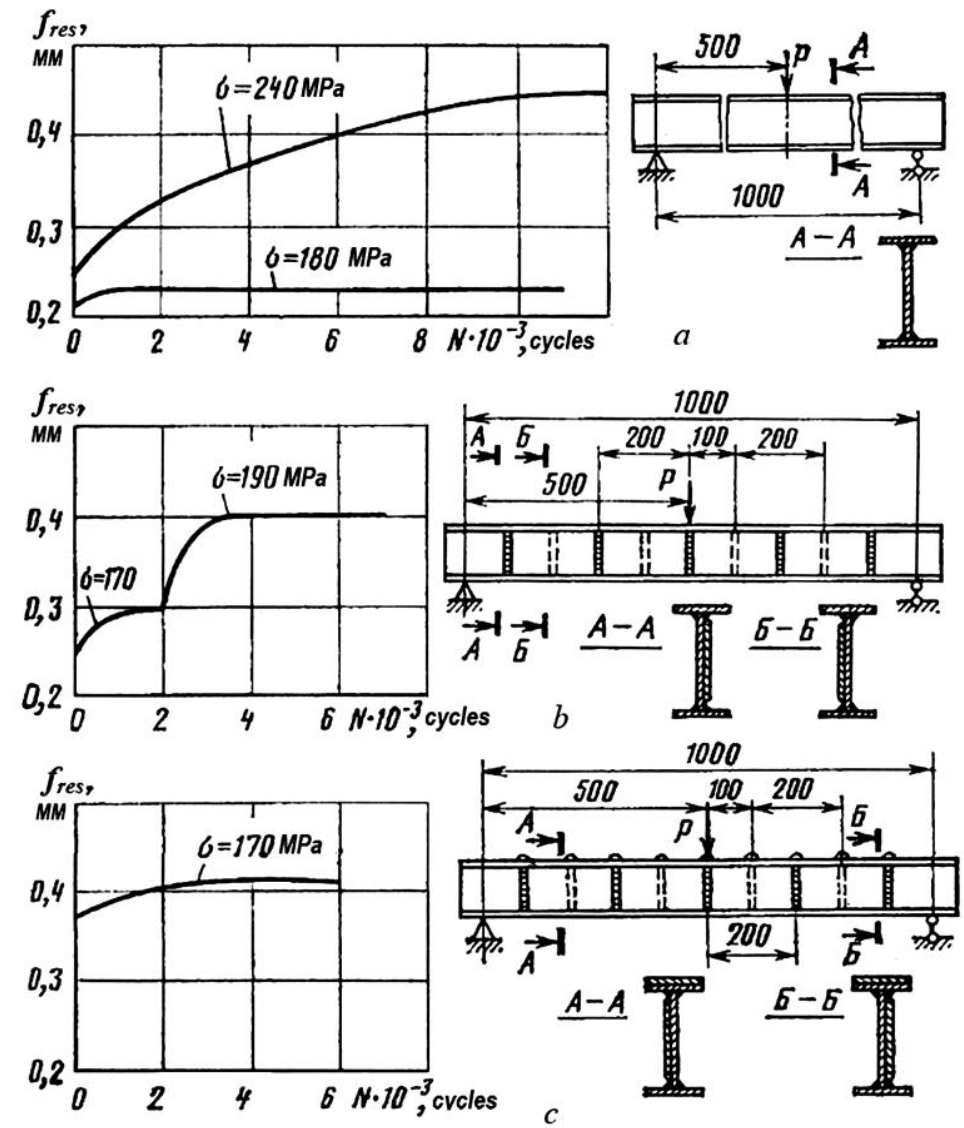

Fig. 2. Dependence of residual welded beam deflections with girth (a), girth and transverse wall (b), girth and transverse wall and top flange (c) welds on the number of cycles during periodic loading 
Beam tests under a periodically varying load applied in the span midpoint were supplemented by moving load tests. As can be seen from the plotting of influence lines, maximum bending moment in each beam cross-section will be greater than when the load acts in the midsection.

The experiment was carried out on a bench with the distance between beam supports equal to $1000 \mathrm{~mm}$. Maximum load was $50 \mathrm{kN}$, load traveling speed was 11, 16, and 33 double strokes per minute.

Beam tests under conditions of the stress type being studied were carried out up to the stress level of $170 \mathrm{MPa}$.

Under the action of moving load, it was observed that beam residual deflections were higher as compared to residual deflections when fixed load of the same level was applied in the span middle. Deflection depth in several beam cross-sections in the initial state and after loading by a moving roller are shown in Fig. 3. Total residual deflection at beam midsection after 40 loading strokes (full cycles) with the stress of $140 \mathrm{MPa}$ amounted to $0.35 \mathrm{~mm}$. This means that if the design camber were 0.001 of the span, then it would have decreased by $35 \%$ after several dozens of load movements.

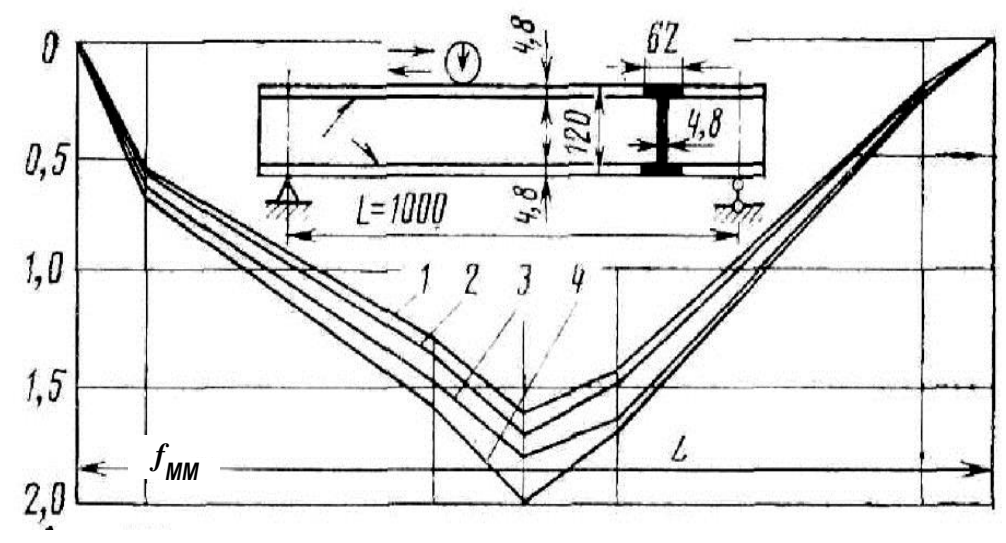

Fig. 3. Distribution of deflections on the beam length under the action of moving load: 1 - initial profile; 2 - after first stroke $(\sigma=110 \mathrm{MPa})$; after 250 strokes $(\sigma=110 \mathrm{MPa}) ; 4-$ after 40 strokes $(\sigma=$ $140 \mathrm{MPa}$ )

After the beam was rolled with a roller under a load corresponding to the stress of 110 $\mathrm{MPa}$, the deflection depth changed from 0.51 to $0.56 \mathrm{~mm}$ over 10 strokes. Residual deflection under a fixed load of the same level was $0.07 \mathrm{~mm}$. Residual deflection under moving load increased by $70 \%$.

When exposed to moving load, as well as to a periodically varying load applied in span midpoint, residual deflection grows as an exhaustive process. $90 \%$ of the maximum residual deflection is achieved over 150-200 strokes. Beam elastic behavior occurs after 250-350 roller strokes under the same level of load.

Residual deflection of beams in equivalent loading conditions depends on the level and distribution area of the maximum residual strain stresses. Maximum residual deflection is observed in the beam structure that includes a combination of longitudinal and transverse welds. The influence of transverse (relative to beam centerline) welding joints on the development of residual deflections is so critical that it must be taken into account when evaluating structures functionality in terms of serviceability limit states.

Repeated loading of welded beam assemblies is defined by accumulation of plastic deformations resulting in the increase of residual deflection. Residual deflection increment decreases, as the number of loading cycles is increased, when external load stresses are less than the material yield strength. Experimental data analysis reveals that residual deflection 
of welded beams under the action of periodically varying load applied in span midsection, or under a moving load, is $(0.2-1)(\mathrm{L} / 1000)$, where $\mathrm{L}$ is the beam span. The value of $\mathrm{L} / 1000$ equals the beam crown that is defined in the beam's design and manufacturing process.

Occurrence of secondary residual deformations is typical for any welded metallic structure of machines, including lifting and transportation, construction and road-building, and other types of machines [12-15].

\section{Conclusions}

1. Deformability of span welded crane beams, including the value of crown, in the operating stage are, to a certain degree, determined by the laws of interaction between stresses produced by external load and residual stresses produced by welding of the crane metallic structure.

2. Residual stresses development can be stabilized by means of its preliminary periodic loading in the range of 300 to 500 cycles using a moving load that corresponds to the maximum design value appropriate for the crane operating conditions.

\section{References}

1. K.D. Nikitin. The fundamental principles of industrial safety. Guidebook. Krasnoyarsk: Siberian Federal University, (2013)

2. RD 10-112-96. Guidelines for inspection of lifting machines with expired lifetime. Part 1. General information.

3. A.V. Vershinsky Maintainability and load-carrying capacity of crane metallic structures. - M.: Mashinostroyenie (1984)

4. S.A. Sokolov Metallic structures of lifting and transportation machines: Guidebook. Saint-Petersburg: Politekhnika (2005)

5. V.I. Braude, M.M. Gokhberg, I.E. Zvyagin et al; Under general editorship of M.M. Gokhberg Crane reference book: In 2 vol. Vol.1/. - L.: Mashinostroyenie, (1988)

6. E.M. Kontsevoy, B.M. Rosenstein Refurbishment of crane metallic structures. - M.: Mashinostroyenie, (1979)

7. EN 12999: 2002. Crants-Loader.-Brussels, (2002)

8. EN 25817: 1992. Arc-welded joints in steel - Guidance on quality levels for imperfection (ISO 5817 : 1999)

9. V.S. Kotelnikov, Yu.A. Yeremin, A.A. Zaretsky, A.A. Korotky The concept of evaluating residual lifetime of lifting crane metallic structures that are past their nominal service lifetime (problem formulation and certain proposals) Industrial labor safety, 10 (2000)

10. V.S. Kotelnikov, V.S. Anisimov, A.A. Zaretsky, A.A. Korotky Development of lifting crane expert inspection methodology Industrial labor safety, 4 (2001)

11. K.D. Nikitin, V.A. Baranov, N.I. Ivashkov, L.N. Gorbunova Development of lifting crane residual lifetime engineering calculations Lifting and transportation technology, 5 (2007)

12. N. Sevryugina, Theor. Foun. of Civil Engin. MATEC Web of Conf., XXVI R-S-P Seminar 2017, 117, 00151 (2017)

13. P. Kapyrin, N. Sevryugina, IOP Conf. Ser.: Mater. Science and Engin., (2018)

14. N. I. Baurova, V. A. Zorin, V. M. Prikhodko, Theor. foundations of chem. eng., 50, 1, (2016)

15. N. I. Baurova, V. A. Zorin, V. M. Prikhodko, Pol. Sc., Ser. D. 9, 2 (2016) 